\title{
Power Quality Distribution Characteristics Analysis for Multi- electrified Railway Traction Load based on Improved Gaussian Mixture Models with Merging Operator
}

\author{
Jinhao Wang ${ }^{1}$, Chaoying Yang ${ }^{1}$, Yuewen $\mathrm{Qi}^{1}$, Yulong Wu ${ }^{1}$, Xiao Chang ${ }^{1}$, \\ Ying Tian $^{2}$, Weiqing Sun ${ }^{2}$ \\ ${ }^{1}$ Electric Power Research Institute, State Grid Shanxi electric power company, \\ 030001 Taiyuan, Shanxi Province, P.R.China \\ ${ }^{2}$ School Optical-Electrical and Computer Enginneering, University of Shanghai for \\ Science and Technology, 200093 Shanghai, P.R.China
}

Keywords: power quality distribution characteristics; electrified railway traction load; improved Gaussian mixture models; merging operator

Abstract: AC-DC electrified locomotive and AC-DC-AC high-speed locomotive are two major electrified railway traction load type, and different types of loads can cause different effects to the power quality of electrified railway traction station. Based on power grid monitoring data of different electrified traction load station, the research using improved Gaussian mixture models with merging operator to establish mixed power quality Gaussian models and obtain power quality distribution characteristics parameters for different electrified railway traction load, which can be used to predict the impact of new railway line to the power grid.

\section{Introduction}

Electrified railway, which uses electrified traction, has received extensive attention from all over the world, since it has the advantages of large traction and low energy consumption. At present, there are two major electrified railway traction load type, include AC-DC electrified locomotive and AC-DC-AC high-speed locomotive in China ${ }^{[1,2]}$. For AC-DC electrified locomotive, such as "Shaoshan" SS4, SS8 and SS9 electrified locomotive series, it is controlled by single-phase thyristor, and its DC traction motor is supplied through the transformer and rectifier, and it has significant low order harmonic ${ }^{[3]}$. It is needed to study the power quality distribution characteristics for different electrified railway traction load, in order to achieve the power quality management.

According to the requirement of State Grid Corporation, all the electrified energy quality parameters such as harmonic, negative sequence, voltage fluctuation and flicker must be monitored. Fuzzy c-means clustering (FCM), due to its simple calculation, becomes the most versatile analysis method for multi-modes problem ${ }^{[4]}$. Meanwhile, the multi-modes process can be expressed by several different Gaussian models, so the Gaussian mixture models (GMM) method can be introduced to describe the multi-modes process ${ }^{[5,6]}$.Yet, traditional GMM method based on the expectation maximization (EM) algorithm, it has the disadvantage of low iterative efficiency.

As for the power quality analysis for different electrified railway traction load in this research, the improved GMM with merging operator is adopted. In this method, the initial model parameters are assumed firstly. Then, the maximum likelihood estimation of current parameters, the distribution parameters re-estimation for data maximum likelihood, the merging operation and change check are calculated alternative iteratively until terminal condition. The parameters of each component when iteration terminated is the power distribution characteristics of different electrified railway traction load, which can be used to analyze the influence of new railway line to the power grid.

\section{Improved Gaussian Mixture Models Monitoring Method with Merging Operator}

Since the power quality of multi-electrified railway traction load can be expressed by several Gaussian mixture models, the GMM monitoring method is adopted to describe the power energy distribution parameters. So the description of GMM monitoring method is given below ${ }^{[7]}$. 
Given training sample set $X$ from non-Gaussian process, it includes $n$ training samples and $x \in X$ is a $m$ dimensional sample. Assuming that the initial value of the parameters in GMM are $\Theta^{(0)}=\left\{\left\{\omega_{1}^{(0)}, \mu_{1}^{(0)}, \sigma_{1}^{(0)}\right\}, \ldots,\left\{\omega_{K_{0}}^{(0)}, \mu_{K_{0}}^{(0)}, \sigma_{K_{0}}^{(0)}\right\}\right\}$, where $K_{0}$ is the initial number of Gaussian components, $\omega_{i}$ is the weight of $i$ th Gaussian component $C_{i}$, which reflects the priori probability that a sample belongs to $C_{i}$. the initial weight of each Gaussian component is $1 / K_{0},\left(\mu_{i}, \sigma_{i}\right)$ is the mean and covariance of $C_{i}$.

In order to establish GMM, the final parameters $\Theta=\left\{\left\{\omega_{1}, \mu_{1}, \sigma_{1}\right\}, \ldots,\left\{\omega_{K}, \mu_{K}, \sigma_{K}\right\}\right\}$ need to be estimated, where $K$ is the final number of Gaussian components. The improved GMM with merging operator is adopted to calculate the parameters. In this method, firstly, the maximum likelihood estimation of the current parameters is calculated, secondly, the distribution parameters are re-estimated to maximum the data likelihood, finally, the merging operation is executed and the change between twice iterations is checked.

The first step is calculating the posterior probability of the $j$ th sample belong to the $k$ th Gaussian component $C_{k}^{\left({ }^{()}\right)}$in the $s$ th iteration

$$
p^{(s)}\left(C_{k}^{(s)} \mid x_{j}\right)=\frac{\omega_{k}^{(s)} g\left(x_{j} \mid \mu_{k}^{(s)}, \sigma_{k}^{(s)}\right)}{\sum_{i=1}^{K} \omega_{i}^{(s)} g\left(x_{j} \mid \mu_{i}^{(s)}, \sigma_{i}^{(s)}\right)}
$$

Where, $g\left(x_{j} \mid \mu_{i}^{(s)}, \boldsymbol{\sigma}_{i}^{(s)}\right)$ is the multivariate Gaussian density function of $x_{j}$ for $C_{i}$,

$$
g\left(x \mid \mu_{i}, \sigma_{i}\right)=\frac{1}{(2 \pi)^{m / 2}\left|\sigma_{i}\right|^{1 / 2}} \exp \left[-\frac{1}{2}\left(x-\mu_{i}\right)^{T} \sigma_{i}^{-1}\left(x-\mu_{i}\right)\right]
$$

And $m$ is the dimension of $x$.

For mixed Gaussian components process, its probability density function is

$$
p(x \mid \mu, \sigma)=\sum_{i=1}^{K} \omega_{i} g\left(x \mid \mu_{i}, \sigma_{i}\right)
$$

The integral of multivariate Gaussian density function for all $x$ satisfies

$$
\int_{R^{m}} p(x \mid \mu, \sigma) d x=\sum_{i=1}^{K} \omega_{i}\left(\int_{R^{m}} g\left(x \mid \mu_{i}, \sigma_{i}\right) d x\right)=1
$$

Since the integral of each Gaussian component probability density is 1 , so

$$
\begin{aligned}
& \sum_{i=1}^{K} \omega_{i}=1 \\
& 0 \leq \omega_{i} \leq 1
\end{aligned}
$$

The second step is re-calculating the distribution parameters according to the data maximum likelihood

$$
\begin{gathered}
\mu_{k}^{(s+1)}=\frac{\sum_{j=1}^{n} p^{(s)}\left(C_{k}^{(s)} \mid x_{j}\right) x_{j}}{\sum_{j=1}^{n} p^{(s)}\left(C_{k}^{(s)} \mid x_{j}\right)} \\
\sigma_{k}^{(s+1)}=\frac{\sum_{j=1}^{n} p^{(s)}\left(C_{k}^{(s)} \mid x_{j}\right)\left(x_{j}-\mu_{k}^{(s+1)}\right)\left(x_{j}-\mu_{k}^{(s+1)}\right)^{T}}{\sum_{j=1}^{n} p^{(s)}\left(C_{k}^{(s)} \mid x_{j}\right)} \\
\omega_{k}^{(s+1)}=\frac{\max \left\{0,\left(\sum_{j=1}^{n} p^{(s)}\left(C_{k}^{(s)} \mid x_{j}\right)\right)-\frac{V}{2}\right\}}{\sum_{i=1}^{K} \max \left\{0,\left(\sum_{j=1}^{n} p^{(s)}\left(C_{k}^{(s)} \mid x_{j}\right)\right)-\frac{V}{2}\right\}}
\end{gathered}
$$

where $\mu_{k}^{(s+1)}, \sigma_{k}^{(s+1)}$ and $\omega_{k}^{(s+1)}$ are the mean, covariance matrix and weight of $C_{k}^{(s+1)}$ respectively, $V=\frac{1}{2} m^{2}+\frac{3}{2} m$.

The third step is executing merging operation and checking the change between twice iterations. Let $C_{i}^{(s)}$ denotes the Gaussian component with smallest weight in $s^{\text {th }}$ iteration, $\omega_{i}^{(s)}$ is the weight of $C_{i}^{(\mathrm{s})}, K_{s}$ is the number of Gaussian components. 


$$
\text { If } \omega_{i}^{(\mathrm{s})}<\frac{1}{K_{0}} \text {, then }
$$

$$
\left\{\begin{array}{l}
\omega_{j}^{(s+1)}=\omega_{j}^{(s)}+\omega_{i}^{(s)} \\
\omega_{i}^{(s+1)}=0
\end{array}\right.
$$

Where $\omega_{j}^{(s)}$ is the weight of $C_{j}^{(\mathrm{s})}$, which has the nearest distance with $C_{i}^{(\mathrm{s})}$.After consolidating $C_{j}^{(\mathrm{s})}$ with $C_{i}^{(\mathrm{s})}$, the first step processes again.

Else if all $\omega_{i}^{(\mathrm{s})}>\frac{1}{K_{0}}$, then checking the parameters change between two iterations whether greater than a certain small value. If yes, then the first step processes again.

When the weights of all Gaussian components are not smaller than $1 / K_{0}$ as well as the parameters change between two iterations is less than the certain small value, the iteration process is terminated and distribution parameters are obtained.

\section{Simulation}

The monitoring data comes from two traction station, the sampling number from each traction station is 5000 , and the sampling interval is 10 seconds. The experimental research process is as follows:

Step 1. Monitoring variable selection. There are more than 200 monitoring variables in monitoring system, according to the importance of those variables, we chose the variables as our monitoring variables, mainly include voltage effective value, current effective value, power, reactive power and apparent power, fundamental power factor, full power factor, fundamental current, third order current harmonic, fifth order current harmonic, seventh order current harmonic, flicker and so on.

Step 2. Through wavelet denoising and data standardization and normalization, the original dataset is constructed.

Step 3. GMM model initialization. Divide the dataset into 10 groups as 10 Gaussian components firstly. Then calculate the initial weights of each Gaussian component as 0.1 as well as the initial mean and covariance of each Gaussian component.

Step 4. Iteration. The iterations is executed through the improved GMM with merging operator, and the mixed Gauss model is established. The iteration process is shown in Figure 1.
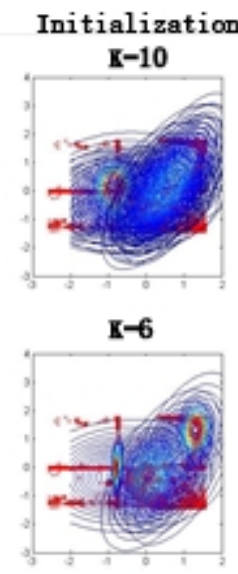
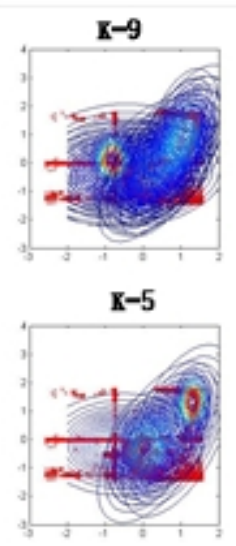

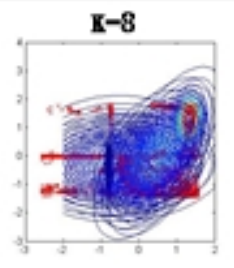

$\mathbf{K}-4$

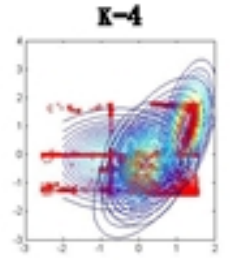

R-7

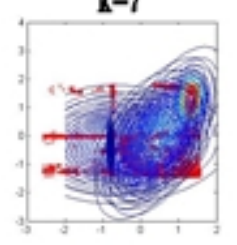

$\mathbf{X}-\mathbf{3}$

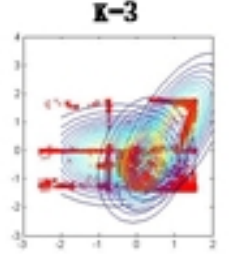

Fig.1. Iteration of creating GMM

The final improved GMM model parameters are shown in Table 1. The final parameters reflect the power quality distribution characteristics for different electrified railway traction load. The table reveals that the all the data can be divided into three different Gaussian components with the priori probability of $0.5347,0.2143$ and 0.2509 respectively. For electrified railway traction load system, it means that the probability of no train is $53.47 \%$, the probability of the first kind of train is $21.43 \%$ and the probability of another kind of train is $25.09 \%$. And the mean as well as covariance 
of these three case are also given in the table, which is the power quality distribution characteristics for different electrified railway traction load.

Table 1 Improved GMM model parameters for power quality of electric railway traction load

\begin{tabular}{|c|c|}
\hline $\begin{array}{l}\text { Model } \\
\text { parameters }\end{array}$ & Value \\
\hline$\omega$ (Weight) & {$\left[\begin{array}{llll}0.5347 & 0.2143 & 0.2509\end{array}\right]$} \\
\hline \multirow{3}{*}{$\begin{array}{ll}\mu & \text { (Mean } \\
\text { value) } & \end{array}$} & 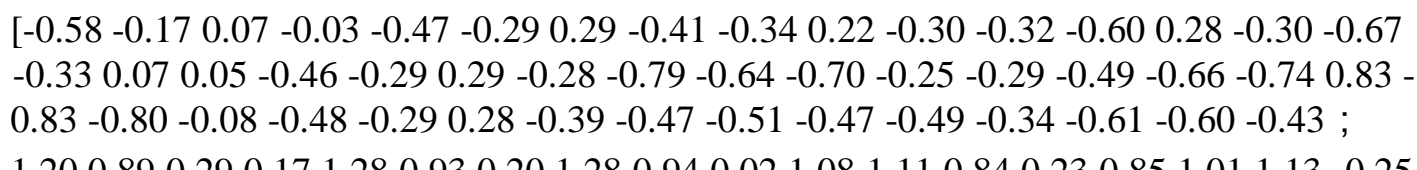 \\
\hline & $\begin{array}{llllllllllllllllllll}1.20 & 0.89 & 0.29 & 0.17 & 1.28 & 0.93 & 0.20 & 1.28 & 0.94 & 0.02 & 1.08 & 1.11 & 0.84 & 0.23 & 0.85 & 1.01 & 1.13 & -0.25 \\
0.71 & 1.22 & 0.93 & 0.21 & 1.09 & 0.82 & 0.46 & 0.76 & 1.04 & 1.05 & 1.25 & 0.89 & 0.72 & -0.79 & 0.80 & 0.74 & 0.04 & 1.28 \\
0.93 & 0.19 & 1.17 & 0.87 & 1.11 & 1.25 & 1.20 & 1.17 & 1.26 & 1.06 & 1.22 ;\end{array}$ \\
\hline & 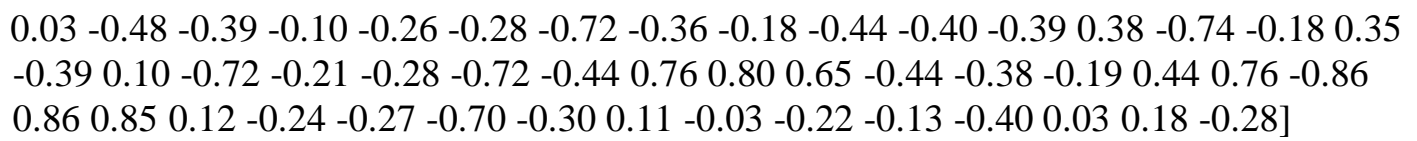 \\
\hline
\end{tabular}

$\sigma$ (Covarianc

e)

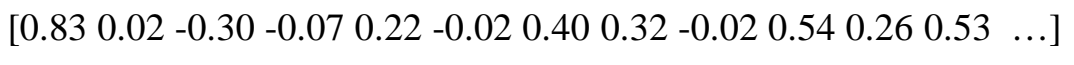

Since the data is standardized, the inverse transform should be performed to obtain the real distributed parameters. The transformation formula is given as follow and the actual characteristic value is shown in Table 2.

$$
\begin{aligned}
& \mathrm{X}_{\text {transform }}=\frac{X-\mathrm{X}_{\text {mean }}}{\mathrm{X}_{\text {std }}} \\
& \mathrm{X}_{\text {mean }}=\operatorname{mean}\left(\mathrm{X}_{\text {origin }}\right) \\
& \mathrm{X}_{\text {std }}=\operatorname{std}\left(\mathrm{X}_{\text {origin }}\right) \\
& \mathrm{X}_{\text {atual }}(\mathrm{i}, \mathrm{j})=\mathrm{X}_{\text {transform }}(\mathrm{i}, \mathrm{j}) * \mathrm{X}_{\text {std }}(1, \mathrm{j})+\mathrm{X}_{\text {mean }}(1, \mathrm{j})
\end{aligned}
$$

\begin{tabular}{|c|c|c|}
\hline $\begin{array}{l}\text { Different } \\
\text { condition }\end{array}$ & weight & Mean of all monitoring variables \\
\hline $\begin{array}{l}\text { No } \\
\text { railway } \\
\text { traction } \\
\text { load }\end{array}$ & 0.5347 & 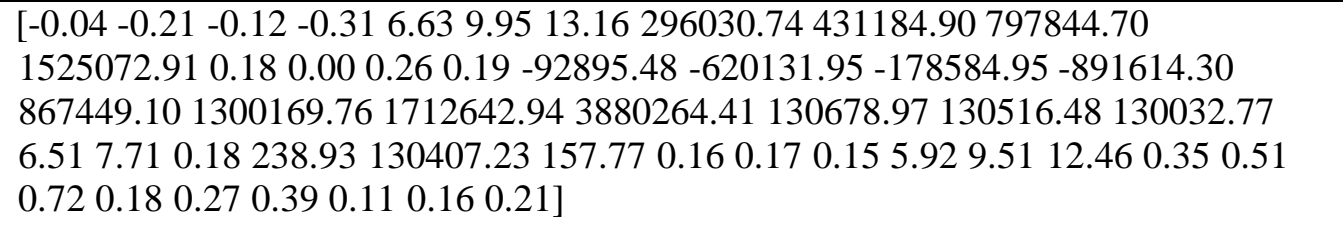 \\
\hline $\begin{array}{l}\text { Railway } \\
\text { traction } \\
\text { load } 1\end{array}$ & 0.2143 & 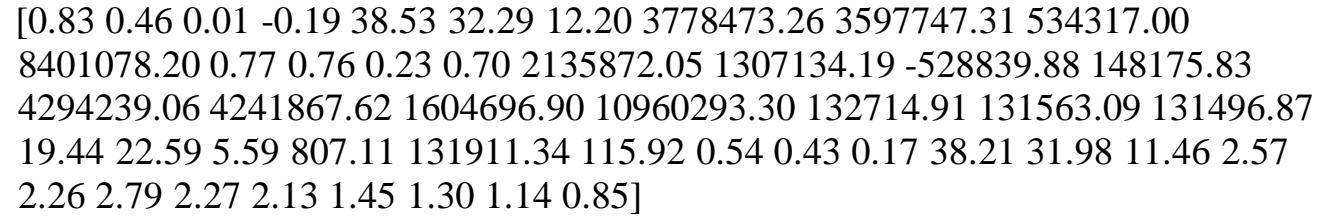 \\
\hline $\begin{array}{l}\text { Railway } \\
\text { traction } \\
\text { load } 2\end{array}$ & 0.2509 & 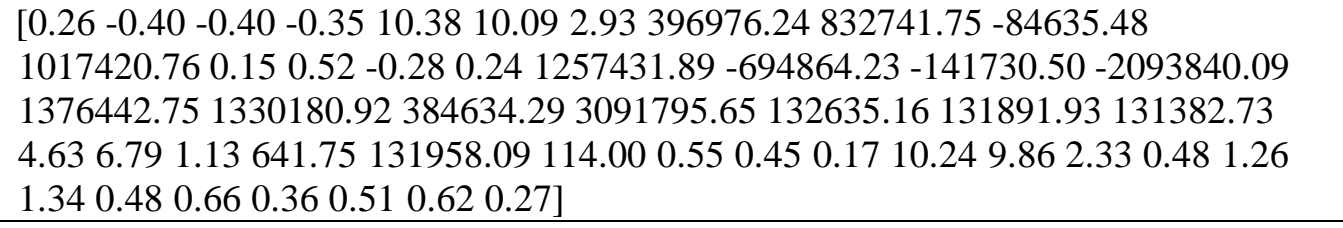 \\
\hline \multicolumn{3}{|c|}{$\begin{array}{l}\text { From table } 3 \text {, lots of information can be obtained. For example, the average value of A phase } \\
\text { damental current absolute value for no railway traction load condition is } 5.9 \mathrm{~A} \text {, that for first } \\
\text { way traction load condition is } 38.2 \mathrm{~A} \text {, that for second railway traction load condition is } \\
2 \mathrm{~A} \text {. The other information such as negative sequence current, positive sequence current, flicker } \\
\text { so on. The information obtained can be used to analysis the influence of the new railway line } \\
\text { traction load to the power grid. }\end{array}$} \\
\hline
\end{tabular}

Table 2 Actual characteristic value for power quality of different electric railway traction load 


\section{Conclusion}

Power quality relates to the type and size of traction load, which is reflected by voltage effective value, current effective value, power, reactive power and apparent power, fundamental power factor, full power factor, harmonic, flicker and so on. This paper adopt improved GMM with merging operator to build the mixed Gaussian models to analysis the power quality distribution characteristics for different electric railway traction load. In this method, the maximum likelihood estimation of the parameters is calculated firstly, the distribution parameters are re-estimated to maximum the data likelihood secondly, the merging operation is executed and the change between twice iterations is checked finally. The final parameters of improved GMM model is the power quality distribution characteristics of different electric railway traction load, which can be used to analysis the influence of the new railway line to the power grid.

\section{Acknowledgements}

This work is supported by National grid science and technology project.

\section{References}

[1].Yang S, Wu M. Study on harmonic distribution characteristics and probability model of high speed EMU based on measured data. Tiedao Xuebao/Journal of the ChinaRailway Society. 2010, 32(3), pp.33-38

[2].Li J,Dou F ,Xia D. Analysis and calculation of harmonic current for Shaoshan IV electric locomotive.Automation of Electric Power Systems. 1999, 23(16), pp.10-13

[3].Han Y, Li J, Huang S, Xia D, Dynamic model and computation of probabilistic harmonic currents for type SS4 locomotive. Automation of Electric Power Systems.2001,25(4),pp.31-36

[4].Ng Y S, Srinivasan R. An adjoined multi-model approach for monitoring batch and transient operations. Computers \& Chemical Engineering. 2009, 33(4), pp.887-902

[5].Yu J, Qin S J. Multimode process monitoring with Bayesian inference-based finite Gaussian mixture models. AIChE journal. 2008, 54(7), pp.1811-1829

[6].Yu J. A nonlinear kernel Gaussian mixture model based inferential monitoring approach for fault detection and diagnosis of chemical processes. Chemical Engineering Science. 2012, 68(1), pp.506-519

[7].Wu Q, Du W, Qian F, Ma Q, Process monitoring with global probability boundary-based on Gaussian mixture model, in: 10th IEEE International Conference on Control and Automation (ICCA), 2013, pp. 789-793 